\title{
NEW QUADRATIC FUNCTIONAL EQUATION AND ITS (HURS)
}

Emel BİÇER*, Department of Mathematics/Faculty of Arts and Sciences, Bingol University, Bingol, ebicer@bingol.edu.tr (iD) https://orcid.org/ 0000-0003-2085-2529)

Received 21.07.2020, Accepted: 01.10.2020

Research Article

*Corresponding author DOI: $10.22531 /$ muglajsci.771906

\section{Abstract}

The primary subject in the stability of differential equations is to answer the question of when is it real that a mapping which roundly satisfies a differential equation must be close to an exact solution of the equation. For this reason, the Hyers-Ulam and Hyers-Ulam Rassias stability of differential equations is fundemantal. Currently, researchers have used various methods (open mapping, direct method, integral factor, fixed point method) to research that the Hyers-Ulam Rassias and Hyers-Ulam stability of differential equations. The direct method has been succesfully apllied for investigate of the Hyers-Ulam Rassias stability of many different functional differential equations. But it does not enough for some important cases. The second most popular method is the fixed point method.

In this study, we make an attemp to establish the Hyers-Ulam Rassias stability (HURS) of a new quadratic type functional equation $(Q F E)$

$$
g(\chi+\gamma+v+\varsigma)+g(\chi-\gamma-v-\varsigma)=4 g(\chi)+g(\gamma+\varsigma)+g(\gamma+\varsigma+2 v)-g(\chi-v)-g(\chi+v)
$$

by direct method and fixed point method. We consider that this research will contribute to the related literature and it may be useful for authors studying on the Hyers-Ulam Stability of the quadratic functional differential equations. Keywords: (HURS), (QFE), fixed point method.

\section{YENI QUADRATIC FONKSIYONEL DENKLEM VE BU DENKLEMİN HYERS ULAM RASSIAS KARARLILIĞI}

\section{Özet}

Diferansiyel denklemlerin kararlılığında asıl mesele bir diferansiyel denklemi yaklaşık olarak sağlayan bir dönüşümün denklemin tam çözümüne yaklaşması ne zaman gerçek olur sorusuna cevap verilmesidir. Bu nedenle diferansiyel denklemlerin Hyers-Ulam ve Hyers Ulam Rassias kararlılı̆̆ı esastır. Bu günlerde araştırmacılar diferansiyel denklemlerin Hyers-Ulam ve Hyers-Ulam Rassias kararlılığını araştırmak için çeşitli metotlar (açık dönüşüm, direkt metot, integral çarpanı, sabit nokta metodu) kullanmaktadır. Direkt metot birçok farklı fonksiyonel diferansiyel denklemlerin HyersUlam Rassias kararlılığını araştırmak için başarılı bir şekilde uygulanmaktadır. Fakat bu metot bazı önemli durumlar için yeterli değildir. İkinci en popüler metot sabit nokta metodudur.

Bu çalışmada direkt metot ve sabit nokta metodunu kullanarak

$$
g(\chi+\gamma+v+\varsigma)+g(\chi-\gamma-v-\varsigma)=4 g(\chi)+g(\gamma+\varsigma)+g(\gamma+\varsigma+2 v)-g(\chi-v)-g(\chi+v)
$$

şeklindeki yeni bir quadratic tipten fonksiyonel denklemin Hyers-Ulam Rassias kararlılığını belirlemek için girişimde bulunduk. Bu araștırmanın quadratic fonksiyonel denklemlerin Hyers Ulam kararlılığı üzerine çalışan yazarlara fayda sağlayabileceğini ve ilgili literatüre katkı sağlayacă̆ını düşünüyoruz.

Anahtar Kelimeler: Hyers-Ulam Rassias kararlılık, quadratic fonksiyonel denklem, sabit nokta metodu.

Cite

Biçer, E., (2020). "New quadratic functional equation and its (HURS) ", Mugla Journal of Science and Technology, 6(2),6368.

\section{Introduction}

In 1940, the concept of Hyers-Ulam stability (HUS) came to light as a result of the problem introduced by Ulam. In 1941, this problem was partially brightened, by Hyers. After then many mathematician have searched this topic.

The following equation

$$
g(\chi+\gamma)+g(\chi-\gamma)=2 g(\chi)+2 g(\gamma)
$$

is named a quadratic functional equation (QFE). Every solution of the (QFE) (1) is said to be a quadratic function.

F. Skof [1] seems to first author who investigated the (HUS) of a (QFE) for functions between $X_{1}$ and $X_{2}$, in which $X_{1}$ is a normed space and $X_{2}$ is a Banach space. 
Cholewa [2] proved that, if $X_{1}$ is an Abelian Grup, then the result of Skof is also true. Czerwik [3] proved the (HURS) of the (QFE) in [1].

Jung [4] studied the (HURS) problems of a (QFE) of the form

$$
\begin{aligned}
& f(\chi-\gamma-z)+f(\chi)+f(\gamma)+f(z) \\
& =f(\chi-\gamma)+f(\gamma+z)+f(z-\chi) .
\end{aligned}
$$

In the literature, it can be seen that (HUS) and (HURS) of (QFEs) can attract the intensive attentions of the researchers. Actually, recently, particularly, the (HUS) and (HURS) of (QFEs) are investigated by many researchers.

In particular, for more results on the (HURS) of (QFE) see the papers [5], [6], [7], [8] and on the (HURS) stability of the ordinary or functional differential equations see the papers [9], [10], [11], [12], [13], [14], [15], [16], [17], [18], [19], [20], [21] and the references therein.

In this study, we deal with a new functional equation:

$$
\begin{aligned}
& g(\chi+\gamma+v+\varsigma)+g(\chi-\gamma-v-\varsigma) \\
& =4 g(\chi)+g(\gamma+\varsigma) \\
& \quad+g(\gamma+\varsigma+2 v)-g(\chi-v)-g(\chi+v) .
\end{aligned}
$$

We prove (HURS) of above (QFE) by using direct method and fixed point method. During the process we use in the following theorem.

Theorem 1.1. ([8]) Let $(X, d)$ be a complete generalized metric space and $P: X \rightarrow X$ be a strictly contractive mapping with Lipschitz constant $L<1$. Then, for each given $\chi \in X$, either

$d\left(P^{n} \chi, P^{n+1} \chi\right)=\infty$

for all $n \geq 0$ or there exists a natural number $n_{0}$ such that

i. $d\left(P^{n} \chi, P^{n+1} \chi\right)<\infty$ for all $n \geq n_{0}$,

ii. The sequence $\left\{P^{n} \chi\right\}$ converges to a fixed point $\gamma^{*}$ of $P$,

iii. $\gamma^{*}$ is the unique fixed point of $P$ in the set $Y=\left\{\gamma \in X: d\left(P^{n_{0}} \chi, \gamma\right)<\infty\right\}$,

iv. $d\left(\gamma, \gamma^{*}\right) \leq \frac{1}{1-L} d(\gamma, P \gamma)$ for all $\gamma \in Y$.

\section{2. (HURS) of (QFE)}

Firstly, we will give a lemma to use in proof of main theorem.

Lemma 2.1. Let $X_{1}$ and $X_{2}$ be real vector spaces. $g: X_{1} \rightarrow X_{2}$ is quadratic if and only if $g$ satisfies equation (2).
Proof. $(\Rightarrow)$ Assume that $g$ is quadratic. Letting $\chi=0=\gamma$ in (1) we obtain $g(0)=0$. Taking $\chi=0$ in (1) gives

$$
g(\gamma)+g(-\gamma)=2 g(0)+2 g(\gamma)
$$

and $g(\gamma)=g(-\gamma)$. Putting $\gamma=\chi$ in (1), we obtain that $g(2 \chi)=4 g(\chi)$.

We substitute $\gamma=\chi+\gamma$ in (1) and then $\gamma=\chi-\gamma$ in (1) to obtain that

$$
g(2 \chi+\gamma)+g(\gamma)=2 g(\chi)+2 g(\chi+\gamma)
$$

and

$g(2 \chi-\gamma)+g(\gamma)=2 g(\chi)+2 g(\chi-\gamma)$.

Adding (3) and (4), we get

$$
g(2 \chi+\gamma)+g(2 \chi-\gamma)=8 g(\chi)+2 g(\gamma) .
$$

Substituting $\gamma=\gamma+v$, in equalities of $g(2 \chi+\gamma)=g(\chi+\gamma+\chi)$,

and

$$
g(2 \chi-\gamma)=g(\chi-\gamma+\chi)
$$

from (1), we obtain

$$
\begin{aligned}
& g(2 \chi+\gamma)=g(\chi+\gamma+\chi+v) \\
& =2 g(\chi+\gamma)+2 g(\chi+v)-g(\gamma-v)
\end{aligned}
$$

and

$$
\begin{aligned}
& g(2 \chi-\gamma)=g(\chi-\gamma+\chi-v) \\
& =2 g(\chi-\gamma)+2 g(\chi-v)-g(v-\gamma) .
\end{aligned}
$$

Adding (6) and (7) and using (5), we arrive at

$$
\begin{aligned}
& g(\chi+\gamma)+g(\chi+v)+g(\chi-\gamma) \\
& +g(\chi-v)-g(\gamma-v) \\
& =4 g(\chi)+g(\gamma+v) .
\end{aligned}
$$

Putting $\gamma=\gamma+v+\varsigma$, in (8), we obtain $g(\chi+\gamma+v+\varsigma)+g(\chi-\gamma-v-\varsigma)$ $=4 g(\chi)+g(\gamma+\varsigma)+g(\gamma+\varsigma+2 v)-g(\chi-v)-g(\chi+v)$.

$(\Leftarrow)$ Substituting $v=0=\varsigma$ in (2) gives the identity

$$
g(\chi+\gamma)+g(\chi-\gamma)=2 g(\chi)+2 g(\gamma)
$$

for all $\chi, \gamma \in X_{1}$, which implies that $g$ is quadratic. The proof is completed.

Given a mapping $g: X_{1} \rightarrow X_{2}$, we define

$$
\begin{aligned}
D g(\chi, \gamma, v, \varsigma)= & g(\chi+\gamma+v+\varsigma) \\
& +g(\chi-\gamma-v-\varsigma)+g(\chi-v) \\
& +g(\chi+v)-g(\gamma+\varsigma+2 v) \\
& -g(\gamma+\varsigma)-4 g(\chi)
\end{aligned}
$$

for all $\chi, \gamma, \nu, \varsigma \in X_{1}$, where $X_{1}$ is a real vector space and $X_{2}$ is a real Banach space.

We investigate the (HURS) of the (QFE) $D g(\chi, \gamma, v, \varsigma)=0$.

Let $\phi: X_{1}^{4} \rightarrow[0, \infty)$ be a function such that 


$$
\lim _{n \rightarrow \infty} \alpha_{p}^{2 n} \phi\left(\frac{\chi}{\alpha_{p}^{n}}, \frac{\gamma}{\alpha_{p}^{n}}, \frac{v}{\alpha_{p}^{n}}, \frac{\varsigma}{\alpha_{p}^{n}}\right)=0
$$

for all $\chi, \gamma, \nu, \varsigma \in X_{1}$, where $\alpha_{p}=\frac{1}{2}$ for $p=0$ and $\alpha_{p}=2$ for $p=1$.

Theorem 2.2. For $g(0)=0$ let $g: X_{1} \rightarrow X_{2}$ be a mapping in which there exists a function $\phi: X_{1}^{4} \rightarrow[0, \infty)$ such that

$$
\|D g(\chi, \gamma, v, \varsigma)\| \leq \phi(\chi, \gamma, v, \varsigma)
$$

for all $\chi, \gamma, v, \varsigma \in X_{1}$. If there exists $L(p)<1$ such that

$$
\varphi(v) \leq \frac{1}{\alpha_{p}^{2}} L \varphi\left(\alpha_{p} v\right)
$$

for all $v \in X_{1}$, in which $\varphi(v)=\phi\left(0,0, \frac{v}{2}, 0\right)$. Then there exists a unique quadratic mapping $Q: X_{1} \rightarrow X_{2}$ satisfying (2) and

$$
\|g(v)-Q(v)\| \leq \frac{L^{1-p}}{1-L} \varphi(v)
$$

for all $v \in X_{1}$.

Proof. Let $M=\left\{h: X_{1} \rightarrow X_{2}, h(0)=0\right\}$ be a set and define the generalized metric on $M$ :

$d(h, f)=\inf \left\{K>0:\|h(v)-f(v)\| \leq K \phi\left(0,0, \frac{v}{2}, 0\right), \forall v \in X_{1}\right\}$.

Then $(M, d)$ is complete.

Let $\Lambda: M \rightarrow M$ be linear mapping such that

$\alpha_{p}^{2} g\left(\frac{v}{\alpha_{p}}\right)=\Lambda g(v)$

for all $v \in X_{1}$. Then for all $h, f \in M$, we obtain $\|h(v)-f(v)\| \leq K \varphi(v), v \in X_{1}$,

$\left\|\alpha_{p}^{2} h\left(\frac{v}{\alpha_{p}}\right)-\alpha_{p}^{2} f\left(\frac{v}{\alpha_{p}}\right)\right\| \leq \alpha_{p}^{2} K \varphi\left(\frac{v}{\alpha_{p}}\right)$,

$\left\|\alpha_{p}^{2} h\left(\frac{v}{\alpha_{p}}\right)-\alpha_{p}^{2} f\left(\frac{v}{\alpha_{p}}\right)\right\| \leq L K \varphi(v)$.

Then, we obtain

$d(\Lambda h, \Lambda f) \leq L d(h, f)$

for all $h, f \in M$. So, $\Lambda$ is a strictly self mapping on $M$.

Putting $\chi=\gamma=\varsigma=0$ in (11), we obtain

$$
\|g(2 v)-4 g(v)\| \leq \phi(0,0, v, 0)
$$

for all $v \in X_{1}$. For the case $p=0$, from (12), we get

$\left\|g(v)-\frac{1}{4} g(2 v)\right\| \leq \frac{1}{2^{2}} \varphi(2 v) \leq L \varphi(v)$

for all $v \in X_{1}$. That is,

$$
d(g, \Lambda g) \leq L \text {. }
$$

Letting $v=\frac{v}{2}$ in (14), we get,

$$
\left\|g(v)-2^{2} g\left(\frac{v}{2}\right)\right\| \leq \varphi(v)
$$

for all $v \in X_{1}$. Using (12) with the case $p=1$, we get

$$
d(g, \Lambda g) \leq L^{0}=1 .
$$

For both situations, by Theorem 1.1, there exists a fixed point $Q$ of $\Lambda$ in $M$ and from Theorem 1.1, $d\left(\Lambda^{n} g, P\right) \rightarrow 0$ as $n \rightarrow \infty$. This implies that,

$$
\lim _{n \rightarrow \infty} \alpha_{p}^{2 n} g\left(\frac{v}{\alpha_{p}^{n}}\right)=Q(v)
$$

holds for all $v \in X_{1}$.

Replacing $\chi, \gamma, v, \varsigma$ by $\frac{\chi}{\alpha_{p}^{n}}, \frac{\gamma}{\alpha_{p}^{n}}, \frac{v}{\alpha_{p}^{n}}, \frac{\varsigma}{\alpha_{p}^{n}}$ in

respectively and multiplying by $\alpha_{p}^{2 n}$, then from (10) and (15) we get

$$
\begin{aligned}
\|D Q(\chi, \gamma, v, \varsigma)\| & =\lim _{n \rightarrow \infty} \alpha_{p}^{2 n}\left\|D g\left(\frac{\chi}{\alpha_{p}^{n}}, \frac{\gamma}{\alpha_{p}^{n}}, \frac{v}{\alpha_{p}^{n}}, \frac{\varsigma}{\alpha_{p}^{n}}\right)\right\| \\
& \leq \lim _{n \rightarrow \infty} \alpha_{p}^{2 n} \phi\left(\frac{\chi}{\alpha_{p}^{n}}, \frac{\gamma}{\alpha_{p}^{n}}, \frac{v}{\alpha_{p}^{n}}, \frac{\varsigma}{\alpha_{p}^{n}}\right)=0
\end{aligned}
$$

for all $\chi, \gamma, v, \varsigma \in X_{1}$. Hence $Q$ satisfies the equation (2). So, $Q$ is quadratic.

Because of $Q$ is the unique fixed point of $\Lambda$ in $S=\{u \in M: d(g, u)<\infty\}, Q$ satisfies in the following inequality

$$
\|g(v)-Q(v)\| \leq K \varphi(v)
$$

for all $v \in X_{1}$ and some $K>0$. From Theorem 1.1, we can write

$$
d(g, Q) \leq \frac{1}{1-L} d(g, \Lambda g),
$$

and we get

$$
d(g, Q) \leq \frac{L^{1-p}}{1-L} .
$$

The proof is completed.

Corollary. Let $X_{1}$ and $X_{2}$ be normed spaces. Let $r \geq 0$ be given. Suppose that $\delta>0$ is fixed. Let $g: X_{1} \rightarrow X_{2}$ be a mapping such that

$$
\|D g(\chi, \gamma, v, \varsigma)\| \leq \delta\left(\|\chi\|^{r}+\|\gamma\|^{r}+\|v\|^{r}+\|\varsigma\|^{r}\right)
$$

for all $\chi, \gamma, v, \varsigma \in X_{1}$. Then the inequality

$\|g(v)-Q(v)\| \leq \frac{\delta}{2^{r}-4}\|v\|^{r}$

holds for all $v \in X_{1}$, in which $r>2$, or

$\|g(v)-Q(v)\| \leq \frac{\delta}{4-2^{r}}\|v\|$ 
holds for all $v \in X_{1}$, where $r<2$.

Proof. Let $\phi(\chi, \gamma, \nu, \varsigma)=\delta\left(\|\chi\|^{r}+\|\gamma\|^{r}+\|v\|^{r}+\|\varsigma\|^{r}\right)$

for all $\chi, \gamma, v, \varsigma \in X_{1}$. Then $L=2^{2-r}$ for $p=1$ or $L=\frac{1}{2^{2-r}}$ for $p=0$, and we get desired results.

\section{3. (HURS) of equation (2) with direct method}

Here, we investigate (HURS) of equation (2) by using the direct method.

Let $D g(\chi, \gamma, v, \varsigma)$ defined as in (9).

Theorem 3.1. Let $\phi: X_{1}^{4} \rightarrow[0, \infty)$ be a mapping such that

$$
\Psi(\chi, \gamma, \nu, \varsigma)=\sum_{j=0}^{\infty} \alpha_{p}^{2 j} \phi\left(\frac{\chi}{\alpha_{p}^{j}}, \frac{\gamma}{\alpha_{p}^{j}}, \frac{v}{\alpha_{p}^{j}}, \frac{\varsigma}{\alpha_{p}^{j}}\right)<\infty
$$

for all $\chi, \gamma, v, \varsigma \in X_{1}$. Assume $g: X_{1} \rightarrow X_{2}$ satisfies inequality (11) for all $\chi, \gamma, v, \varsigma \in X_{1}$. Then

$\lim _{n \rightarrow \infty} \alpha_{p}^{2 n} g\left(\frac{v}{\alpha_{p}^{n}}\right)=Q(v)$

exists for each $v \in X_{1}$ and describes unique quadratic mapping $Q: X_{1} \rightarrow X_{2}$ such that

$$
\|g(v)-Q(v)\| \leq \alpha_{p}^{2(1-p)} \Psi\left(0,0, \frac{v}{\alpha_{p}^{p}}, 0\right)
$$

for all $v \in X_{1}$.

Proof. Since $\Psi(0,0,0,0)=\sum_{j=0}^{\infty} \alpha_{p}^{2 j} \phi(0,0,0,0)<\infty$, setting $\chi=\gamma=\varsigma=0$ in (11) we have

$$
\|4 g(v)-g(2 v)\| \leq \phi(0,0, v, 0)
$$

for all $v \in X_{1}$. Interchanging $v$ with $\frac{v}{2}$ in (19), we arrive at

$$
\left\|4 g\left(\frac{v}{2}\right)-g(v)\right\| \leq \phi\left(0,0, \frac{v}{2}, 0\right) .
$$

Replacing $v$ by $\frac{v}{\alpha_{p}^{n-1}}$ and multiplying both sides by $\alpha_{p}^{2(n-1)}$, in formerly inequality, we get

$$
\left\|4 \alpha_{p}^{2(n-1)} g\left(\frac{v}{2 \alpha_{p}^{n-1}}\right)-\alpha_{p}^{2(n-1)} g\left(\frac{v}{\alpha_{p}^{n-1}}\right)\right\| \leq \alpha_{p}^{2(n-1)} \phi\left(0,0, \frac{v}{2 \alpha_{p}^{n-1}}, 0\right)
$$

for all $v \in X_{1}$ and $n \in N$. Then from (20) and (21), we deduce that for $p=1$,

$$
\left\|\alpha_{p}^{2 n} g\left(\frac{v}{\alpha_{p}^{n}}\right)-g(v)\right\| \leq \sum_{k=0}^{n-1} \alpha_{p}^{2 k} \phi\left(0,0, \frac{v}{\alpha_{p}^{k+1}}, 0\right)
$$

and

$$
\left\|4 g\left(\frac{v}{2}\right)-\alpha_{p}^{2(n-1)} g\left(\frac{v}{\alpha_{p}^{n-1}}\right)\right\| \leq \sum_{k=1}^{n} \alpha_{p}^{2 k} \phi\left(0,0, \frac{v}{\alpha_{p}^{k-1}}, 0\right)
$$

for $p=0$. Replacing $v$ by $2 v$ in (23), we obtain

$$
\left\|g(v)-\alpha_{p}^{2 n} g\left(\frac{v}{\alpha_{p}^{n}}\right)\right\| \leq \frac{1}{4} \sum_{k=0}^{n-1} \alpha_{p}^{2 k} \phi\left(0,0, \frac{v}{\alpha_{p}^{k}}, 0\right)
$$

for all $v \in X_{1}$ and any positive integer $n$.

Now, we show that the sequence $\left\{\alpha_{p}^{2 n} g\left(\frac{v}{\alpha_{p}^{n}}\right)\right\}$ is a Cauchy sequence. For any $m \in N$, by (22) we have

$\left\|\alpha_{p}^{2(n+m)} g\left(\frac{v}{\alpha_{p}^{n+m}}\right)-\alpha_{p}^{2 m} g\left(\frac{v}{\alpha_{p}^{m}}\right)\right\|=\alpha_{p}^{2 m}\left\|\alpha_{p}^{2 n} g\left(\frac{v}{\alpha_{p}^{n+m}}\right)-g\left(\frac{v}{\alpha_{p}^{m}}\right)\right\|$

$\leq \alpha_{p}^{2 m} \sum_{k=0}^{n-1} \alpha_{p}^{2 k} \phi\left(0,0, \frac{v}{\alpha_{p}^{k+m+1}}, 0\right)$

$\leq \frac{1}{4} \sum_{k=0}^{n-1} \alpha_{p}^{2(k+m+1)} \phi\left(0,0, \frac{v}{\alpha_{p}^{k+m+1}}, 0\right)$.

By condition (17), we obtain

$$
\lim _{n \rightarrow \infty} \sum_{k=0}^{n-1} \alpha_{p}^{2(k+m+1)} \phi\left(0,0, \frac{v}{\alpha_{p}^{k+m+1}}, 0\right)=0,
$$

for all $v \in X_{1}$. Consequently, $\left\{\alpha_{p}^{2 \mathrm{n}} g\left(\frac{v}{\alpha_{p}^{n}}\right)\right\}$ is a Cauchy sequence.

Similarly, we can also show that $\left\{\alpha_{p}^{2 n} g\left(\frac{v}{\alpha_{p}^{n}}\right)\right\}$ is a Cauch sequence by considering of inequality (24).

Thus, we can set

$$
Q(v)=\alpha_{p}^{2 n} g\left(\frac{v}{\alpha_{p}^{n}}\right)
$$

for all $v \in X_{1}$.

Now, we show that, $Q$ is a solution of equation (2).

Replacing $\chi, \gamma, v, \varsigma$ by $\frac{\chi}{\alpha_{p}^{n}}, \frac{\gamma}{\alpha_{p}^{n}}, \frac{v}{\alpha_{p}^{n}}, \frac{\varsigma}{\alpha_{p}^{n}}$ in (11), respectively.

If we multiply both sides of obtained equation by $\alpha_{p}^{2 n}$, we get 
$\alpha_{p}^{2 n}\left\|D g\left(\frac{\chi}{\alpha_{p}^{n}}, \frac{\gamma}{\alpha_{p}^{n}}, \frac{v}{\alpha_{p}^{n}}, \frac{\varsigma}{\alpha_{p}^{n}}\right)\right\|$

$\leq \alpha_{p}^{2 n} \phi\left(\frac{\chi}{\alpha_{p}^{n}}, \frac{\gamma}{\alpha_{p}^{n}}, \frac{v}{\alpha_{p}^{n}}, \frac{\varsigma}{\alpha_{p}^{n}}\right)$.

Since $\lim _{n \rightarrow \infty} \alpha_{p}^{2 n} \phi\left(\frac{\chi}{\alpha_{p}^{n}}, \frac{\gamma}{\alpha_{p}^{n}}, \frac{v}{\alpha_{p}^{n}}, \frac{\varsigma}{\alpha_{p}^{n}}\right)=0$, the mapping $Q$ satisfies (2). From (22) we obtain

$\lim _{n \rightarrow \infty}\left\|\alpha_{p}^{2 n} g\left(\frac{v}{\alpha_{p}^{n}}\right)-g(v)\right\| \leq \lim _{n \rightarrow \infty} \sum_{k=0}^{n-1} \alpha_{p}^{2 k} \phi\left(0,0, \frac{v}{\alpha_{p}^{k+1}}, 0\right)$.

We can also obtain above ineqality using (24). So, above inequality holds both for $p=1$ and for $p=0$. Consequently, we get

$$
\|g(v)-Q(v)\| \leq \alpha_{p}^{2(1-p)} \Psi\left(0,0, \frac{v}{\alpha_{p}^{p}}, 0\right)
$$

for all $v \in X_{1}$.

We should show that the uniqueness of $Q$. Suppose that there exists $Q^{\prime}: X_{1} \rightarrow X_{2}$ such that $Q(v)$ not equivalents to $Q^{\prime}(v)$. Then

$$
\begin{aligned}
\left\|Q(v)-Q^{\prime}(v)\right\|= & \alpha_{p}^{2 n}\left\|Q\left(\frac{v}{\alpha_{p}^{n}}\right)-Q^{\prime}\left(\frac{v}{\alpha_{p}^{n}}\right)\right\| \\
\leq & \alpha_{p}^{2 n}\|\| Q\left(\frac{v}{\alpha_{p}^{n}}\right)-f\left(\frac{v}{\alpha_{p}^{n}}\right) \| \\
& \left.+\left\|f\left(\frac{v}{\alpha_{p}^{n}}\right)-Q^{\prime}\left(\frac{v}{\alpha_{p}^{n}}\right)\right\|\right) \\
\leq & 2 \alpha_{p}^{2(n+1-p)} \Psi\left(0,0, \frac{v}{\alpha_{p}^{n+p}}, 0\right) \\
& \leq \frac{2}{\alpha_{p}^{4 p-2}} \alpha_{p}^{2(n+p)} \Psi\left(0,0, \frac{v}{\alpha_{p}^{n+p}}, 0\right) .
\end{aligned}
$$

Since $\lim _{n \rightarrow \infty} \alpha_{p}^{2(n+p)} \Psi\left(0,0, \frac{v}{\alpha_{p}^{n+p}}, 0\right)=0$, we get $Q(v)=Q^{\prime}(v)$, for all $v \in X_{1}$.

\section{Conclusion}

A new quadratic functional equation was considered. The Hyers-Ulam Rassias stability of this quadratic equation was investigated. We benefited from fixed point method and direct method.

\section{References}

[1] Skof, F. "Proprieta locali e approssimazione di operatori", Rend. Sem. Mat. Fis. Milano, 53. No., 113$129,1983$.
[2] Cholewa, P.W. "Remarks on the stability of functional equations", Aequationes Math., 27., 76-86, 1984.

[3] Czerwik, S. Functional Equations and Inequalities in Several Variables, World Scientific, Singapore, 2002.

[4] Jung, S. M. "On the Hyers-Ulam-Rassias stability of a quadratic functional equation", J. Math. Anal. Appl., 232., 384-393, 1999.

[5] Jung, S. M. "On the Hyers-Ulam stability of the functional equations that have the quadratic property", J. Math. Anal. Appl., 222., 126-137, 1998.

[6] Lee, Y. W. "On the stability of a quadratic Jensen type functional equation", J. Math. Anal. Appl., 270., 590-601, 2002.

[7] Park, C. and Rassias, T.M. "Fixed Points and generalized Hyers-Ulam Stability of Quadratic Functional Equations", Journal of Mathematical Inequalities, 1.4., 515-528, 2007.

[8] Aoki, T. "On the stability of the linear transformation in Banach spaces", J. Math. Soc. Japan, 2. 64-66, 1950.

[9] Biçer, E. and Tunç, C. "On the Hyers-Ulam stability of certain partial differential equations of second order", Nonlinear Dyn. Syst. Theory. 17. 2., 150-157, 2017.

[10] Biçer, E. and Tunç, C. "On the Hyers -Ulam stability of Laguerre and Bessel equations by Laplace transform method", Nonlinear Dyn. Syst. Theory, 17. 4., 340-346, 2017.

[11] Biçer, E. and Tunç, C. "New Theorems for HyersUlam Stability of Lienard Equation with Variable Time Lags", International Journal of Mathematics and Computer Science, 13. 2., 231-242, 2018.

[12] Kenary, H. A., Rezaei, H., Gheisari, Y., Park, C. "On the stability of set-valued functional equations with the fixed point alternative", Fixed Point Theory Appl., 17 pages 2012 .

[13] Diaz, J. B. and Margolis, B. "A fixed point theorem of the alternative for contractions on a generalized complete metric space", Bull. Amer. Math. Soc., 74. 305-309, 1968.

[14] Shen, H.Y. and Lan, Y. Y. "On the general solution of a quadratic functional equation and its Ulam stability in various abstract spaces", J. Nonlinear Sci. Appl., 7., 368-378, 2014.

[15] Ulam, S.M. Problems in Modern Mathematics, Wiley, New York, 1964.

[16] Tunç, C. and Biçer, E. "Hyers-Ulam stability of non-homogeneous Euler equations of third and fourth order", Scientific Research and Essays. 8.5., 220-226, 2013.

[17] Tunç, C. and Biçer, E. "Hyers-Ulam-Rassias stability for a first order functional differential equation", J. Math. Fundam. Sci. 47. 143-153, 2015.

[18] Rassias, T. M. "On the Stability of the Linear Mapping in Banach Spaces", Proc. Amer. Math. Soc., 72., 297-300, 1978. 
[19] Hyers, D. H. "On the Stability of the Linear Functional Equation", Proc. Nat. Acad. Sci. 27., 222224, 1941.

[20] Başcl, Y., Öğrekçi, S., Mısır, A. “On Hyers-Ulam stability for fractional differential equations including the new Caputo Fabrizio fractional derivative", Mediterranean Journal of Mathematics 16: 130-144, 2019.

[21] Başcl, Y., Mısır, A., Öğrekçi, S. "On the stability problem of differential equations in the sense of Ulam", Results in Mathematics 75, 2020. 